\title{
From needs to actions: prospects for planned adaptations in high mountain communities
}

\author{
Graham McDowell $^{1}$ (D) - Leila Harris ${ }^{1} \cdot$ Michele Koppes $^{1} \cdot$ Martin F. Price $^{2}$ (D) \\ Kai M.A. $\operatorname{Chan}^{1}$ (D) - Dhawa G. Lama ${ }^{3}$
}

Received: 6 April 2020 / Accepted: 28 October 2020 / Published online: 20 November 2020

(C) The Author(s) 2020

\begin{abstract}
Adaptation needs in high mountain communities are increasingly well documented, yet most efforts to address these needs continue to befall mountain people who have contributed little to the problem of climate change. This situation represents a contravention of accepted norms of climate justice and calls attention to the need for better understanding of prospects for externally resourced adaptation initiatives in high mountain areas. In response, this paper examines the architecture of formal adaptation support mechanisms organized through the United Nations Framework Convention on Climate Change (UNFCCC) and how such mechanisms might help to meet adaptation needs in high mountain communities. It outlines key global adaptation initiatives organized through the UNFCCC, clarifies idealized linkages between these global adaptation initiatives and meeting local adaptation needs, and evaluates actual progress in connecting such support with discrete adaptation needs in the upper Manaslu region of Nepal. The paper then critically examines observed shortcomings in matching adaptation support organized through the UNFCCC with local adaptation needs, including complications stemming from the bureaucratic nature of formal adaptation support mechanisms, the intervening role of the state in delivering aid, and the ways in which these complexities intersect with the specific socio-cultural contexts of mountain communities. It concludes by highlighting several prospects for increasing the quantity and quality of adaptation support to mountain communities. These opportunities are considered alongside several salient concerns about formal adaptation support mechanisms in an effort to provide a well-rounded assessment of the prospects for planned adaptations in high mountain communities.
\end{abstract}

Keywords Adaptation $\cdot$ UNFCCC $\cdot$ Climate change $\cdot$ Mountains $\cdot$ Nepal $\cdot$ Himalayas

Graham McDowell

grahammcdowell@gmail.com

Extended author information available on the last page of the article 


\section{Introduction}

Mountain regions are home to an array of cultural, ethnic, and linguistic groups and are associated with most biodiversity hotspots, making them globally important centres of biocultural diversity (Gardner et al. 2013; Price and Kohler 2013). They are also conspicuous bellwethers of climate change (Huss et al. 2017), with emerging evidence suggesting that mountain regions are warming at twice the global average (Palazzi et al. 2019; Pepin et al. 2015). Such warming is dramatically altering living conditions for the $\sim 915$ million people residing in mountain areas, many of whom are already burdened by poverty, food insecurity, and exclusion from social support services (FAO 2015). This combination of climatic changes and persistent socio-economic marginalization is leading to widespread vulnerability in mountain communities, particularly in mountain areas of the Global South (Carey et al. 2017; FAO 2015; Hock et al. 2019). In this context, there is a growing focus in mountain research on human adaptation (Adler et al. 2019), with efforts to study and implement responses to climate change in mountain areas now well documented (McDowell et al. 2019). Contemporaneously, mechanisms of adaptation support organized through the United Nations Framework Convention on Climate Change (UNFCCC)-which we define as formal institutions involved in supporting planned adaptation actions - are becoming well established, and international commitments to meeting the needs of the most vulnerable are becoming more specific and forceful (e.g. Paris Agreement's Global Goal on Adaptation) (Lesnikowski et al. 2017; Magnan and Ribera 2016). Notwithstanding growing material and political support for adaptation at the international level, there is currently little clarity about progress in, and specific opportunities for, matching international adaptation support with adaptation needs in mountain communities at the frontlines of climate change.

In response, this paper outlines key global adaptation mechanisms organized through the UNFCCC; clarifies idealized linkages between these global adaptation initiatives and meeting local adaptation needs; and then evaluates actual progress in leveraging such support to address community-identified adaptation needs in the high mountains of Nepal, focusing on a case study of the upper Manaslu region of Nepal. This study area shares environmental and social characteristics akin to those found in many other high mountain areas in the Global South. The paper then critically examines observed shortcomings in matching adaptation support mechanisms organized through the UNFCCC with local adaptation needs, including complications stemming from the bureaucratic nature of adaptation support mechanisms, the intervening role of the state in delivering aid, and the ways in which these complexities intersect with the specific socio-cultural contexts of mountain communities. It concludes by identifying key prospects for better aligning formal adaptation support with adaptation needs in high mountain communities.

We acknowledge that adaptation support organized through the UNFCCC is not the only option for addressing vulnerabilities in (and beyond) mountain areas. For example, support for adaptation from multinational organizations and NGOs is important in many areas. Moreover, we emphasize that external support may not be necessary or appropriate where mountain communities are able to draw effectively on their own local knowledge, resources, and capabilities to address climate-related challenges and opportunities (McDowell et al. 2014). We therefore do not claim that leveraging support organized through the UNFCCC is the only or best approach to addressing the profound and growing challenges of climate change vulnerability in mountain areas. However, the UNFCCC plays a paramount role in establishing principles and priorities for adaptation, normalizing adaptation action, and facilitating the 
distribution of significant adaptation resources (Ford et al. 2016). Moreover, the Convention text specifically recognizes that 'developing countries with fragile mountainous ecosystems are particularly vulnerable to the adverse effects of climate change' (UNFCCC 1992 p. 2) and highlights the need for adaptation action in mountainous contexts (Article 4). For these reasons, we believe that an examination of adaptation initiatives organized by the UNFCCC is particularly germane for addressing adaptation needs in mountain areas.

\section{Adaptation to climate change in high mountains}

\subsection{Theoretical foundations}

Our engagement with adaptation is informed by the definition of Moser and Ekstrom (2010): 'Adaptation involves changes in social-ecological systems in response to actual and expected impacts of climate change in the context of interacting non-climatic changes. Adaptation strategies and actions can range from short-term coping to longer-term, deeper transformations, aim to meet more than climate change goals alone, and may or may not succeed in moderating harm or exploiting beneficial opportunities' (p. 22026). The ability to adapt to climatic stressors is determined by social factors such as educational attainment and gender dynamics that affect access to information, assets, and social safety nets (Adger 2006; Smit and Wandel 2006). Accordingly, differentiated vulnerability to similar climatic stimuli is often observed as a function of pre-existing social inequities and depravations (Ribot 2014), as increasingly documented in mountain areas (Carey et al. 2017; Gentle and Maraseni 2012; McDowell et al. 2013; Shukla et al. 2017). Combating vulnerability therefore requires adaptations that address the root causes of susceptibility to harm-poverty, marginalization, discrimination (Ford and Smit 2004; Lemos et al. 2007; Ribot 2011) - although this is not often an explicit objective of mainstream climate change adaptation efforts (Bassett and Fogelman 2013; Ensor et al. 2019).

Similarly, adaptations are thought to be more effective when they are embedded within efforts to address concurrent social and environmental concerns (Wilbanks and Kates 2010). This is consistent with insights from resilience thinking, which suggests that increasing 'specific resilience' (e.g. climate specific adaptations) can jeopardize 'general resilience' and the capacity of socio-ecological systems to persist or reorganize when faced with multiple stresses (Folke et al. 2010). Beyond addressing material constraints and other non-climatic social and environmental stressors, recent mountain-focused research highlights the importance of considering the socio-cultural dimensions of adaptation, including perceptions, values, and ontologically disparate local/traditional and Western/scientific understandings of climatic changes (Gagné et al. 2014; Kaul 2019; Mills-Novoa et al. 2017; Orlove et al. 2019).

Adaptations can be thought of as either 'hard' or 'soft' (Sovacool 2011). Hard adaptations represent responses that rely predominantly on human-built infrastructure, involve socioecological disturbances, and tend to lack flexibility (e.g. constructing a dam for flood protection). Hard adaptations can effectively protect life and property from acute threats like glacial lake outburst floods (GLOFs), but they can also exacerbate stresses on ecosystems already under threat from climatic changes and other more proximate stresses (Díaz et al. 2019; Turner et al. 2010). A growing body of literature is revealing viable alternatives to reliance on hard infrastructure. For example, work on green infrastructure (e.g. Matthews et al. 2015) and nature-based solutions (e.g. Cohen-Shacham et al. 2016) provide insights into adaptation 
options that can protect people and ecosystems by leveraging natural capital, local ecological knowledge, and low-impact technologies (e.g. restoring riparian ecosystems for flood protection) (see Jones et al. 2012 for elaboration). Such soft responses locate adaptations within broader concerns about biodiversity conservation and maintaining ecosystem services (Egan and Price 2017) and aim to cultivate co-benefits between people and ecosystems in times of change (Chan et al. 2019).

Other soft adaptations draw on insights from contextual vulnerability and community-based adaptation literature (e.g. Ayers and Forsyth 2009; Ford et al. 2010) and aim to reduce social inequities and depravations by building institutional capacity, increasing community assets, and reducing socio-economic disparities. Such interventions draw attention to the broader political economy of adaptation and aim to ameliorate underlying determinants of susceptibility to harm, including through the pursuit of transformative adaptations (Kates et al. 2012; Ribot 2011).

Adaptations can also be classified as 'autonomous' or 'planned' (Smit et al. 2000). Autonomous adaptations are less formal in their development and implementation and are widely observed in many rural and Indigenous communities at the frontlines of climate change (Ford et al. 2014; McDowell et al. 2019). They can be appropriate in areas where local resilience is high and knowledge of socio-ecological dynamics is well developed (Ford et al. 2020; Mishra et al. 2019; Thornton and Manasfi 2010); however, they can also signify situations where relations with formal planning entities are limited or strained (McDowell et al. 2014). Planned adaptations are the primary focus of international climate policy (Khan and Roberts 2013); they represent more structured approaches to adaptation and include initiatives such as those supported by the UNFCCC-related adaptation support examined in this article. While planned adaptations are thought to play an important role in supporting wellinformed and well-resourced responses to climate change (Füssel 2007), it is nevertheless important to critically examine both the socio-cultural and political context within which formal mechanisms of adaptation support are formed as well as the ways in which planned interventions intersect with and modify specific socio-ecological realities (Khan and Roberts 2013; Nagoda and Nightingale 2017; Ojha et al. 2016).

\subsection{Status of adaptation in high mountain areas}

The IPCC Special Report on the Oceans and Cryosphere in a Changing Climate (SROCC) synthesizes available information about the status of adaptation action in high mountain systems (Hock et al. 2019). For example, adaptation action has increased since the first global assessment of adaptation in mountain areas (see McDowell et al. 2014). However, most adaptations continue to be autonomous reactions to experienced climatic stimuli that are devised and carried out without reference to a formal adaptation plan (McDowell et al. 2019; Rasul et al. 2019). Although some autonomous responses might represent effective adaptations by resilient mountain communities, the widespread marginalization of mountain people in the Global South (FAO 2015) suggests that the prevalence of autonomous adaptations is indicative of inadequate adaptation support. This leads to trepidation about the viability of adaptations that are devised under duress and in the context of limited resources and information. Indeed, widely documented vulnerabilities to climate change in the Himalayas and mountain areas more broadly suggest that many adaptation efforts - autonomous or otherwise - are insufficient to address even current levels of climatic stress (Carey et al. 2017; Hock et al. 2019). Furthermore, autonomous adaptations may deplete already scarce 
community resources, with the effect of worsening pre-existing socio-economic difficulties. In this context, concern about the status of adaptation in mountain areas is well founded and widely reported (Adler et al. 2019; McDowell et al. 2014, 2019; Muccione et al. 2016; Rasul et al. 2019; Sud et al. 2015). It is therefore critical to know more about the availability of resources for planned adaptations in high mountain communities, including mechanisms of support organized under the banner of the UNFCCC, the ways in which such support reaches (or does not reach) frontline communities, and opportunities for improving the fit between available support and community needs, preferences, and aspirations.

\section{Nepal case study}

Nepal is a mountainous developing country (Human Development Index, HDI-0.579) where there is evidence of acute adaptation needs in mountain areas as well as significant efforts to address climate-related challenges (McDowell et al. 2019; Mishra et al. 2019; Rasul et al. 2019; Sud et al. 2015). Adaptation needs emerge largely as a result of climate-related changes such as rising temperatures, glacial recession, and changing precipitation dynamics as well as social factors that increase sensitivity and reduce adaptability such as reliance on resource-based livelihoods, limited state support, and poverty (Bolch et al. 2019; Gioli et al. 2019; Sapkota et al. 2016). Such climatic and non-climatic drivers of vulnerability are also common in other high mountain areas of the Global South (Hock et al. 2019). However, Nepal stands out in terms of its focus on adaptation in mountain areas as well as its progress in securing formal support for adaptation programmes and projects, including through UNFCCC adaptation initiatives. Nepal therefore provides a unique opportunity to evaluate a best-case scenario in terms of efforts by a mountainous least developed country (LDC) to secure and mobilize adaptation support available through UNFCCC channels.

We focus specifically on progress in meeting adaptation needs in the upper Manaslu region, a high mountain area located in the northern Gorkha District $\left(\sim 28^{\circ} 26^{\prime} \mathrm{N}, 84^{\circ} 54^{\prime} \mathrm{E}\right)$. The region contains the planet's 8th highest peak-Manaslu $(8156 \mathrm{~m})$-and is home to $\sim 9000$ ethnic Tibetans who rely heavily on agropastoral livelihoods (NTNC 2019). In situ studies of climate-related change for the region are lacking, but analysis by Robson et al. (2018) based on remotely sensed imagery reveals significant changes in regional glacial systems. Buddhist ethical and moral principles continue to influence life among the region's highly diverse mountain ecosystems and extensively glacierized landscapes (Childs 2004; Plachta 2018; Robson et al. 2018). However, road building efforts, the 2015 Nepal earthquake, and an emerging tourism economy also shape contemporary outlooks (Bennike 2017, 2018, 2019). The upper Manaslu region was designated as a conservation area in 1998. Subsequent programmes by the Manaslu Area Conservation Program have brought some attention and investment to the area, but the region remains relatively poor and underserviced, with little in the way of infrastructure or health and education facilities (NTNC 2019). The nature of adaptation needs in upper Manaslu (discussed below) share characteristics with those reported across many high mountain areas. We therefore pursue an analysis of progress in meeting adaptation needs in upper Manaslu as a case study for shedding light on the prospects (and perils) of meeting adaptation needs in high mountain areas through UNFCCC adaptation mechanisms more broadly. 


\section{Methods}

This study draws on content analysis, narrative literature review, and community-level research in upper Manaslu to enrich and validate study findings through the combination and cross-checking of information from grey literature and database sources, peer-reviewed articles, and stakeholders in Nepal (see Eisner 1991 for more on validation through mixed methods).

The content analysis (method 1) focused on clarifying the architecture, mandates, and protocols for action of major UNFCCC adaptation initiatives as well as how UNFCCC adaptation assistance has been sought for, and woven into, Nepal's adaptation planning activities. Materials evaluated were identified through a purposive selection process that involved reviewing official websites of the UNFCCC, Government of Nepal, and related institutions such as the Global Environment Facility (which manages several adaptation funds); pursuing materials recommended by adaptation policy experts familiar with UNFCCC and/or Nepal adaptation initiatives; and scanning the bibliographies of key resources to identify materials not retrieved through the procedures above. Reviewed items included official documents and decisions (grey literature) as well as official databases, all of which were examined for content relevant to support for planned adaptations in low income mountainous countries (following methodological guidance from Bengtsson 2016; Payne and Payne 2004). Only materials available in English were evaluated. This analysis served to elaborate the official landscape and narratives of UNFCCC adaptation initiatives as well as existing Government of Nepal adaptation efforts.

A narrative literature review (method 2) was used to identify peer-reviewed articles focused on adaptation efforts organized through the UNFCCC, government-led adaptation action in Nepal, and critical appraisals of global to local adaptation support efforts. Narrative reviews seek to obtain a broad overview of available evidence regarding a specific topic and can be used appropriately in situations where it is not necessary to quantify trends and patterns in the literature (i.e. as is done in systematic reviews) (Sutton et al. 2019). Documents were identified through Google Scholar searches using titles from key documents, decisions, and programmes/ projects as well as terms such as "UNFCCC" "Adaptation", "Mountains", and "Nepal". Returned article titles and abstracts were reviewed to identify papers with a substantive focus on adaptation support mechanisms of the UNFCCC, planned adaptation efforts in Nepal, and/ or delivery of adaptation support from global to local levels. Germane articles were read thoroughly to identify relevant insights and arguments. Information from these articles helped to situate insights from the content analysis within broader scholarly debates and led to a better understanding of congruence and discord between global adaptation initiatives, Government of Nepal efforts, and on-the-ground adaptation outcomes.

Community-level work (method 3) was carried out in the high mountain communities of Chhule and Samagaun (as elaborated in McDowell et al. in review), both of which are located at $\sim 3500 \mathrm{~m}$ in the upper Manaslu region of the central Nepal Himalayas. The research methods-including 80 household interviews, 24 key informant interviews, and 2 focus groups - were carried out by local research partners from the study region and benefited from the research team's contextual knowledge and fluency in local dialects. A questionnaire comprised of both closed and open choice questions was used for household interviews to collect information in a manner that promoted flexibility between known topics of interest and topics that emerged during discussion. Summary statistics was performed to characterize responses for closed choice questions; responses to open choice questions and text from key 
informant interviews and focus groups were reviewed for further details of vulnerability and adaptation. The case study is pertinent for identifying community-level adaptation needs as well as evaluating progress in meeting those needs through adaptation support organized under the banner of UNFCCC.

\section{The architecture of UNFCCC adaptation initiatives}

The UNFCCC plays a key role in establishing and reinforcing norms for international climate action and is the centrepiece of global climate governance (Betsill et al. 2015). The primary objective of the Convention is mitigation; that is, to 'prevent dangerous anthropogenic interference with the climate system' (Article 2) (UNFCCC 1992). Adaptation is rarely mentioned in the 1992 Convention text, although it recognizes two forms of adaptation support: capacity-building and financial assistance (Article 4) (Khan and Roberts 2013). Here, assistance is viewed as coming from high-income countries and flowing to low-income countries, consistent with the principle of 'common but differentiated responsibilities and respective capabilities' (Article 3). With growing awareness of unavoidable climatic changes, particularly following landmark IPCC assessment reports in 2001 and 2007, adaptation began to gain prominence in UNFCCC texts and decisions (Ford et al. 2016). However, it was not until the 16th meeting of the Conference of Parties (COP 16) in Cancun in 2010 that the international community formally agreed that 'adaptation must be addressed with the same priority as mitigation' (Cancun Agreements - section I, paragraph 2(b)) (UNFCCC 2011). The 'Lima call for climate action' (COP 20, Lima, 2014) went on to stress the specific needs of Indigenous peoples in adaptation planning and action while the 'Paris Agreement' (COP 21, Paris, 2015) includes a Global Goal on Adaptation (goal 7) with concrete objectives for adaptation action (Ford et al. 2016; Lesnikowski et al. 2017; Magnan and Ribera 2016).

Growing emphasis on adaptation in UNFCCC negotiations since the early 2000s has led to the establishment of a specific architecture of adaptation-focused 'workstreams' and funding entities (Fig. 1). Such initiatives offer technical support and procedural guidance for countryled adaptation planning in low-income countries, as well as financial support for adaptation planning processes and the implementation of specific adaptation projects. The mandates of adaptation workstreams and funds differ slightly, but all aim to advance specific normative goals agreed upon (or accepted) over the course of nearly three decades of UNFCCC negotiations. For example, while National Adaptation Programmes of Action (NAPA) and National Adaptation Plans (NAP) focus on meeting immediate adaptation needs in LDCs and medium- to long-term adaptation needs in low-income countries, respectively, both embody mechanisms for targeting equity-focused capacity building efforts and financial assistance, consistent with Article 3 of the Convention. Procedurally, requests for adaptation support are initiated (or endorsed) by low-income nation states while the provision of adaptation support is the responsibility of high-income countries. Notably, developed countries have committed to providing \$100 billion USD per year by 2020 to support climate action in low-income countries (see Cancun Agreements, UNFCCC 2011), suggesting that funding organized through the UNFCCC will be highly relevant for adaptation projects in mountain areas in coming years. However, there is uncertainty about current levels of funding and therefore some concern that developed nations are not on track to meet this pledge (Donner et al. 2016; Weikmans and Roberts 2019). 


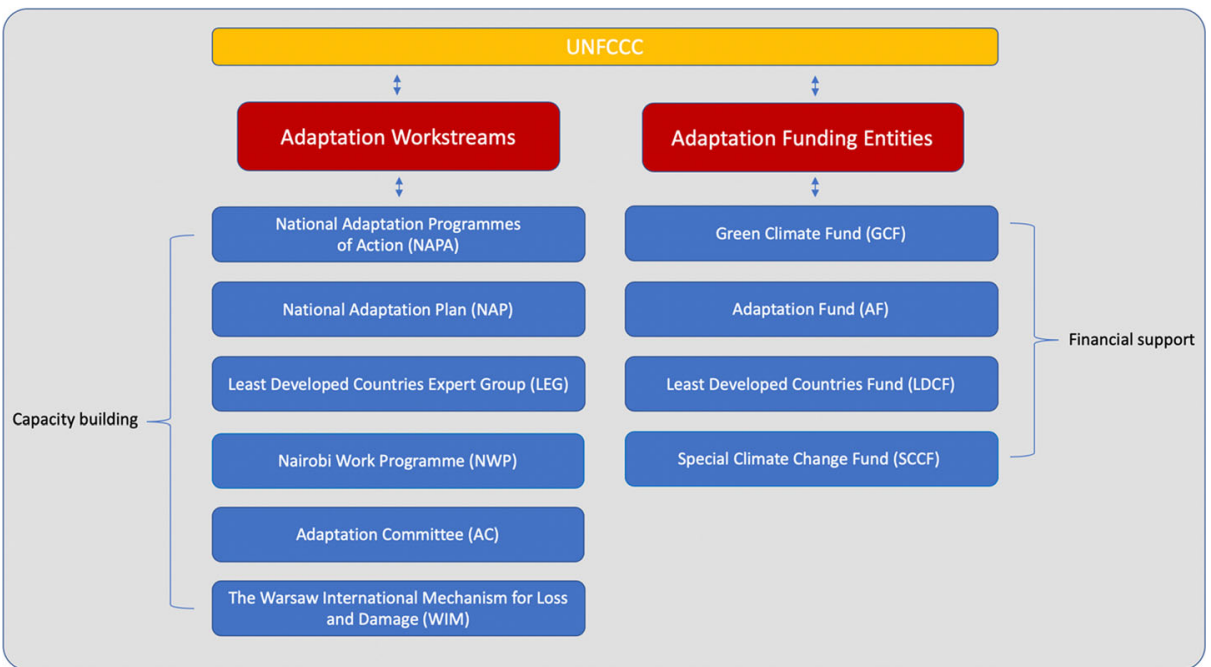

Fig. 1 Architecture of UNFCCC adaptation initiatives

\section{The intervening role of the state}

The Government of Nepal has sought and received adaptation support from various UNFCCC workstreams and funding entities. Adaptation became a focal area of national policy in 2009 with the establishment of the Climate Change Council, which is chaired by the prime Minister and guides high-level planning and coordination related to Nepal's climate change activities. The country completed its NAPA in 2010. This specified nine adaptation priority areas including mountain-specific topics, such as GLOF monitoring, as well as mountain-relevant topics, such as supporting community-based disaster management and empowering vulnerable communities through improved water management schemes (MoE 2010b). Notably, both the NAPA and the Government's 2011 Climate Change Policy have a heavy focus on communitylevel action, including mandates stating that at least $80 \%$ of the available climate finance budget be used to implement local-level programmes (GoN 2011a; MoE 2010b).

To operationalize local action, the Government initiated a Local Adaptation Plans for Action (LAPA) programme in 2011 to aid the 'delivery of adaptation services to the most climate-vulnerable areas and people' (GoN 2011b p. 2). There are seven major steps in the LAPA process: sensitization; vulnerability and adaptation assessment; prioritization of adaptation options; formulation of the adaptation plan; integration of the adaptation plan into regular planning processes; implementation of the adaptation plan; and progress assessment (ibid.). This innovative model for supporting local adaptation action has been emulated in other mountainous countries such as India, Pakistan, Kenya, and Tanzania (Maharjan 2019). Nepal's LAPA programme provides a formal framework for identifying local adaptation needs, integrating sub-national priorities into national-level adaptation planning, and, in turn, accessing support to implement local-level adaptations (Silwal et al. 2019); it receives major implementation support from the Nepal Climate Change Support Programme (NCCSP) (Vij et al. 2019). These efforts were complemented by subsequent policies aimed at facilitating the integration of climate concerns into broader development plans and programmes (see NPC 
2011) and addressing the health dimensions of climate change (see MoH 2015). Since 2015, Nepal has been involved in the NAP process, which has goals of identifying medium- to longterm adaptation needs and further integrating climate change adaptation in policies, programmes, and activities across sectors and institutional levels (MoFE 2018).

Nepal's adaptation efforts have led to the establishment of several government planning and coordination institutions (Fig. 2). These developments are indicative of envisioned connections between UNFCCC adaptation initiatives and climate action in low-income countries. Until 2018, the Ministry of Population and Environment (MoPE) was in charge of Nepal's adaptation-related activities and was the focal point for UNFCCC contact. However, following government restructuring in 2018, such responsibilities now fall under the purview of the Ministry of Forests and Environment (MoFE) (MoFE 2018).

Since the early 2000s, Nepal has received $\sim \$ 37$ million (USD) in adaptation-specific funding from UNFCCC funding entities (Mahat et al. 2019). Such funds have supported numerous adaptation projects (in addition to the adaptation planning processes cited above), including inter alia a GLOF risk reduction programme supported by the Least Developed Countries Fund in Solukhumbu and a food security initiative in mountainous Karnali districts supported by the Adaptation Fund. However, both Dixit et al. (2016) and Mahat et al. (2019) note that to date multi- and bi-lateral funding for adaptation projects has been significantly greater than contributions from funding streams organized through the UNFCCC. Such support amounts to $\sim \$ 168$ million (USD) since the early 2000s, with major contributors including the UK Department for International Development, US Agency for International Development, Asian Development Bank, and World Bank (Mahat et al. 2019). However, multi- and bi-lateral funding contributions fall well short of the estimated \$2.4 billion (USD) needed to secure climate resilience in agriculture, hydroelectricity, and water-induced disasters in Nepal by 2030 (MoSTE 2014). Thus, while such funding is significant, it does not supplant the need for financial support from UNFCCC funding entities.

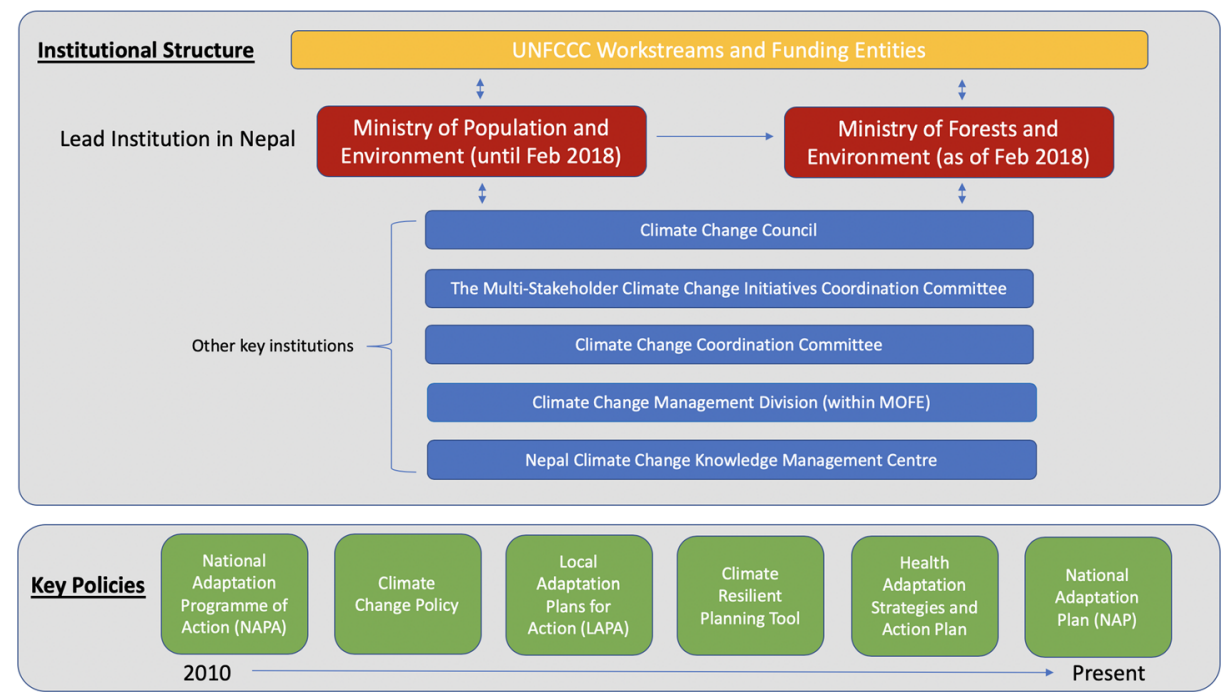

Fig. 2 Government of Nepal institutional structure and policies related to adaptation - non-exhaustive 


\section{Adaptation needs in upper Manaslu, Nepal}

Community-level research in the upper Manaslu region focused on characterizing lived experiences of climate-related changes in glacio-hydrological systems (see McDowell et al. in review for elaboration), an analytical focus that responds to growing awareness of interdependencies between climate change, the cryosphere, and society in high mountain areas (Carey et al. 2017; Hock et al. 2019; Huss et al. 2017; McDowell and Koppes 2017; Scott et al. 2019). More than $80 \%$ of residents reported reductions in glacier and snow cover over the last 10 years. The most widely reported hydrological effects of these changes were increasingly frequent and intense summer floods in local waterways; respondents indicated that these changes are exacerbated by increases in the intensity of summer rainfall events. These observations are consistent with scientific understanding of climate-related hydrological changes in the Nepal Himalayas (Bolch et al. 2019; Scott et al. 2019).

Recent flooding events have destroyed local homes, watermills, bridges, and trails; tragically, children have also drowned during such floods. Community members have drawn on past experience with hydrological variability to cope with contemporary water-related challenges and have built makeshift stone barriers along waterways adjacent to key infrastructure to protect lives and community assets. However, the increasing frequency and intensity of flooding - in the context of material, financial, and technical constraints - has overwhelmed the efficacy of these autonomous responses. Indeed, only $14 \%$ of community members who are affected by flooding state that their adaptive responses have moderated harm.

Community members emphasized two high-priority adaptation needs: flood protection measures and climate change education programmes. The former are needed to safeguard people and community assets from increasingly frequent and powerful floods. The latter are needed to enable local anticipatory adaptation planning efforts through the provision of information about trajectories of climate-related hydrological changes. Meeting adaptation needs identified by community members in upper Manaslu should not be overly complex or resource-intensive; these needs represent straightforward opportunities for reducing vulnerabilities in high mountain communities. They also fall within the purview of adaptation support envisioned through the UNFCCC and are consistent with the type of vulnerability reduction strategies envisioned in Nepalese adaptation support efforts (e.g. LAPAs).

\section{Progress in meeting adaptation needs}

Notwithstanding the apparently laudable adaptation programmes and policies the Government of Nepal has advanced with support of UNFCCC initiatives, we found no evidence in published materials of adaptation projects supported by UNFCCC workstreams or funding entities in upper Manaslu. This state of affairs was confirmed by community members, who reported no significant adaptation assistance from outside the region. This situation stands alongside NAPA vulnerability mapping efforts that ranked Gorkha District as highly vulnerable (MoE 2010a), suggesting deficits in the delivery of adaptation support despite nearly 10 years of acknowledged need. We recognize that some projects supported by UNFCCC initiatives in other districts have addressed adaptation needs comparable to those in upper Manaslu (e.g. the aforementioned GLOF risk reduction programme in Solukhumbu), but nevertheless observe a pattern of gaps in the delivery of formal adaptation support to Himalayan mountain communities facing vulnerabilities related to hydrological changes and 
other climatic stressors. Why is this the case given the significant support available through UNFCCC workstreams or funding entities, major state-led adaptation efforts, and clear adaptation needs at the community-level?

One explanation is the complex and bureaucratic nature of accessing resources from formal UNFCCC workstreams and funding entities. Progress is also hampered to some extent by mountain topography and limited transportation infrastructure. However, copious evidence of research and development organizations working in hard-to-reach areas of the Himalayas illustrates that remoteness does not pre-determine exclusion from outside assistance (Hewitt and Mehta 2012). Local action has also been slowed by the prodigious effort required to complete the LAPA process with communities across Nepal. To date, most LAPA effort has been concentrated in the far-west region of Nepal, which is considered particularly vulnerable (Maharjan 2019).

Another possible explanation is competing demands on the state. However, adaptation is clearly a central priority for the Government of Nepal; it has remained high on the agenda despite the dramatic effects of the 2015 earthquake (e.g. MoFE 2018), the promulgation of a new constitution later that year, and the subsequent restructuring of the government in 2018. These events have certainly influenced adaptation planning and implementation efforts, including a growing focus on disaster risk reduction and revisions to the LAPA framework (see Vij et al. 2018; Vij et al. 2019 for elaboration). However, it appears as though the (limited) capacity of the government, rather than a lack of government intention, is the larger hurdle to action on the ground. Looking forward, state capacity should continue to grow with ongoing UNFCCC support (e.g. through the NAP process) and experience gained from initiatives such as the NCCSP, and this will likely lead to increased project implementation in mountain communities. But greater state capacity will not necessarily translate into appropriate locallevel adaptation initiatives.

Nightingale (2017) has demonstrated that struggles for authority and recognition have strongly influenced adaptation policies and institutions in Nepal, with attendant effects on where, how, and for whom adaptation assistance becomes available across rural Nepal. Similarly, Vij et al. (2019) highlight how power asymmetries among participants in LAPA planning meetings led to the prioritization of actions that reflected the preferences of specific actors, primarily the facilitators of meetings and local politicians, not community members. As such, adaptation planning activities can actually reinforce, rather than alleviate, the social conditions that shape differentiated vulnerabilities (Nagoda and Nightingale 2017). This inauspicious situation has been documented in other studies of the LAPA process (e.g. Silwal et al. 2019), and points to the importance of power dynamics in shaping the implementation of planned adaptations (Few et al. 2007). Furthermore, some have argued that local adaptation planning efforts have tended to focus on addressing vulnerability to the impacts of climate change per se without addressing the wider social context within which susceptibility to harm emerges (Ensor et al. 2019; Ojha et al. 2016). Here, the UNFCCC tenet of supporting efforts that address the 'additional effects of climate change' can conflict with the fact that mountain communities often desire responses that address multiple, concurrent, and often long-standing environmental and social changes (Eriksen et al. 2015; O'Brien and Leichenko 2000). For example, the desire for flood-resistant infrastructure in upper Manaslu is entwined with broader economic development considerations related to the need for safe and reliable bridges for trekkers.

More broadly, UNFCCC adaptation workstreams and funding entities - and by extension state-led planning programmes like LAPAs - tend to embody a specific globalized discourse 
that can conflict with the material and symbolic ways in which mountain populations understand climate-related changes (Gagné et al. 2014; Jurt et al. 2015; Mills-Novoa et al. 2017). For example, while the UNFCCC focuses on mitigation and adaptation to address climate change (i.e. climate change as a problem to be solved), residents of upper Manaslu often conceive climate change as a symptom of larger social-spiritual improprieties (i.e. climate change as a call to piety). Indeed, deep commitments to Buddhism lead many residents to prioritize proper religious practices over efforts to address material threats posed by climatic changes, believing that piety is in fact the means of addressing the root causes of susceptibility to harm. Such differences in the ways that problems are framed can make it difficult for communities to secure support for locally relevant responses that do not resonate with the discursive norms of the UNFCCC (Nagoda 2015). Such complexities have been well elaborated in pioneering work by Kaul (2019) on traditional metaphysical convictions, spiritualities, moralities, and emotionalities associated with geohazards in the Indian Himalayas, work that highlights the importance of 'two eyed seeing' in navigating responses to climatic stressors in mountain regions. These insights call attention to the complex ways in which formal adaptation support intersects with specific socio-cultural contexts and suggests a need for attention not only to what support is available, but also to whose voice counts in adaptation planning, who can meaningfully access adaptation support, and how such support can be utilized.

Despite significant progress in Nepal in initiating large-scale, cross-sectoral, and locally focused adaptation programmes and policies at the national level, progress in implementing actual adaptation projects in vulnerable mountain communities, such as those in upper Manaslu, remains limited. Although the abovementioned reasons for observed shortcomings in the quantity and quality of adaptation support were identified in relation to the Nepalese experience, we believe they represent generalizable barriers likely to be encountered in other mountainous countries in the Global South (e.g. limited state capacity, funding constraints, power struggles, different worldviews of adaptation planning officials and local communities). As such, we have drawn on these insights to outline generalizable opportunities for increasing the flow of appropriate adaptation support to vulnerable mountain communities.

\section{Prospects for connecting UNFCCC initiatives with needs in mountain communities}

There are at least four opportunities for increasing the quantity and quality of adaptation support from UNFCCC workstreams and funding entities to high mountain communities in Nepal and the Global South more broadly.

\subsection{Prospects for increasing formal adaptation support}

First, projects supported by the Adaptation Fund (AF) and the Green Climate Fund (GCF) can be designed, proposed, and implemented by non-state actors. Specifically, a direct access modality allows for the accreditation and subsequent flow of funds to organizations working at regional, national, or sub-national scales (called implementing entities under the AF and direct access entities under the GCF). In principle, such entities could include organizations working at these scales in mountain areas of the Global South. Such accreditation will likely be easier to secure for well-established organizations such as the International Centre for Integrated Mountain Development (ICIMOD) and the Consortium for the Sustainable Development of 
the Andean Eco-region (CONDESAN); however, the GCF provides capacity building funds to support smaller or less well-established organizations in preparing applications for accreditation. Once accredited, such organizations could work collaboratively with mountain communities to develop proposals for locally appropriate adaptation initiatives, serving as 'translators' between the world views and aspirations of mountain residents and the objectives of UNFCCC funding entities. This is a key opportunity to prioritize the preferences and aspirations of mountain people in adaptation efforts and, in the process, to begin addressing some of the power dynamics and knowledge politics cited above.

It is important to recognize, however, that organizational accreditation requires an endorsement from the national governments; this could be difficult to obtain in countries where the state is complicit in the marginalization of highland populations and might not want to draw attention to mountain inequities (Debarbieux and Rudaz 2015). Nevertheless, the fact that organizations working in mountain areas can seek accreditation as implementing entities/direct access entities represents an important opportunity for increasing the amount of support for, and quality of, planned adaptations in high mountain communities.

Second, while the two remaining UNFCCC funding entities do not have a direct access modality for non-state actors, the Special Climate Change Fund (SCCF) explicitly mentions support for projects in mountains as well as water management, flood protection, and risk reduction efforts. Coherence between the mandate of this fund and issues relevant to mountain communities such as those in upper Manaslu could make the SCCF a germane target for governments seeking support for mountain-focused projects (e.g. funding to implement LAPA projects across the Nepal Himalaya). Indeed, the SCCF has already funded several mountainspecific projects (e.g. integrating climate change risks into water and flood management by vulnerable mountainous communities in the Greater Caucasus region of Azerbaijan, GEF 2019b). Furthermore, while the mandate of the SCCF states that support is limited to projects addressing the additional impacts of climate change (often interpreted as a prioritization of hard adaptations), in practice, several projects that have been supported by the SCCF take the form of soft adaptations (see ibid.). Thus, the SCCF might offer support for proposals that take a more holistic approach to addressing climate change vulnerability in mountain communities, including nature-based approaches that might better serve mountain people who rely directly on mountain-sourced ecosystem services (Palomo 2017). In addition, the SCCF provides support for projects in all low-income countries (i.e. Non-Annex I), not just LDCs, making it relevant for mountainous countries such as Peru that do not qualify for support from other UNFCCC funding entities.

Access to SCCF funds requires governments to co-develop proposals with a Global Environment Facility (GEF) Partner Agency. Fortuitously, the Food and Agriculture Organization of the United Nations (FAO), which hosts the Mountain Partnership Secretariat, is one such agency. This serendipitous thematic (mountains) and institutional (FAO/Mountain Partnership) alignment represents another salient opportunity for increasing support for planned adaptation projects in mountain areas.

Third, the growing focus on Indigenous peoples in UNFCCC decisions and processes is another positive development for securing formal adaptation support for Indigenous living communities in mountain areas, although significant shortcomings remain (see Belfer et al. 2019; Shawoo and Thornton 2019). For example, greater awareness of the often disproportionate effects of climate change in Indigenous peoples as well as the essential role of Indigenous knowledge in adaptation planning (as enshrined in UNFCCC 2015 Article 7.5) echoes insights from community-based vulnerability and adaptation research in high mountain 
communities (as summarized in Hock et al. 2019). There is an opportunity to highlight these synergies in project proposals and a growing likelihood that UNFCCC funding entities will be receptive to projects that engage with the needs and knowledge of Indigenous peoples in mountain regions. Furthermore, principles and obligations outlined in the United Nations Declaration on the Rights of Indigenous Peoples (UNDRIP) can be highlighted to increase justification for support for locally appropriate adaptation projects with Indigenous communities.

Of course, not all mountain areas are inhabited by Indigenous peoples, and even where proposals are framed around Indigenous issues, governments that are not sympathetic to the needs or representation of Indigenous peoples might foreclose this opportunity. Despite these caveats, growing recognition of Indigenous peoples in UNFCCC decisions and among UN institutions more broadly can be (rightly) leveraged to justify support for adaptation projects in Indigenous communites in high mountain areas.

Lastly, adaptation support organized through he UNFCCC is now being conceptualized within the goals of broader global initiatives, namely, the Sustainable Development Goals (SDGs) and the Sendai Framework for Disaster Risk Reduction (UN Climate Change Secretariat 2017). In this context, proposals that are synergistic with these allied initiatives are likely to be viewed more favourably, a fortunate development given the recognized relevance of these initiatives for mountain areas (Wymann von Dach et al. 2017; Wymann von Dach et al. 2018). For example, in sensitive mountain environments where hard adaptations could lead to unintended ecological impacts, striving for coherence with the SDGs can lead to more environmentally sound responses to climate change (e.g. goal 15.4-'Ensure the conservation of mountain ecosystems, including their biodiversity, in order to enhance their capacity to provide benefits that are essential for sustainable development' United Nations 2015 p. 29). Recognition of such complementarities can also help to justify support for soft adaptations that are attentive to the human and ecological dimensions of climate change. The 'Ecosystem-Based Adaptation for climate-resilient development in the Kathmandu Valley, Nepal' project is one example of the type of initiatives that can emerge when adaptation is situated within broader sustainability considerations (GEF 2019a).

Likewise, given the growing frequency and magnitude of hazards being faced by mountain communities (Hock et al. 2019; Huss et al. 2017), aligning proposals with the Sendai Framework for Disaster Risk Reduction represents an opportunity to operationalize key recommendations from the broader risk reduction community (as per Wymann von Dach et al. 2017). Mountain-focused adaptation initiatives are an ideal venue for showcasing complementarities between adaptation, SDGs, and the Sendai Framework, and proposals with this laudable objective are likely to be especially attractive in the current funding context.

The challenge of climate change in high mountains cannot be met without adaptation actions that address the interwoven scientific, human, and socio-ecological dimensions of climate change (McDowell et al. 2019). While adaptations implemented with support from UNFCCC initiatives do not guarantee success in these areas, we believe that the focus of such initiatives on supporting science-based, stakeholder-engaged, and sustainability focused adaptations provides a promising basis for planned adaptation actions in mountain areas.

\subsection{Limitations}

This assessment is subject to several limitations. For example, our insights were primarily developed in relation to one mountainous country and a sub-region therein. Although we 
suspect that many of our observations are broadly applicable, our findings are inevitably skewed by our focus on Nepal. In addition, we have not outlined the full procedural details for securing adaptation support from the respective workstreams and funding entities described herein. Moreover, we have alluded to some power dynamics at play in UNFCCC and government-led adaptation programmes but have not evaluated the potentially problematic nature of interactions between mountain organizations and mountain communities. Organizations working with mountain communities must also be cognizant of issues related to power and positionality; ethical engagements between mountain organizations and communities are a precondition of tenable co-developed proposals for adaptation support. More broadly, we have only focused on adaptation support organized through the UNFCCC, yet there is an evergrowing range of other formal adaptation support mechanisms that may be relevant to mountain communities (e.g. direct project funding from multinational agencies). In view of these limitations, this assessment represents a provisional and partial view of prospects for planned adaptations in high mountain communities.

\section{Conclusions}

This assessment represents an effort to move from aspirations of more just, equitable, and sustainable futures for mountain people at the frontlines of climate change, to a focus on the means of achieving such outcomes. It clarified the architecture of available adaptation support organized through the UNFCCC and provides an empirically grounded evaluation of whether such formalized support mechanisms are having tangible effects on addressing adaptation needs in high mountain communities. Drawing on a case study of Nepal and adaptation needs in the upper Manaslu region, it identified country-specific and generalizable reasons for discordance between idealized pathways of adaptation support from global institutions to local communities, including complications stemming from the bureaucratic nature of formal adaptation mechanisms, the intervening role of the state in delivering aid, and the ways in which these complexities intersect with the specific socio-cultural contexts of mountain communities. It then highlighted several prospects for increasing the quantity and quality of adaptation support to mountain communities: (1) formalizing relationships between organizations working in mountain areas and UNFCCC funding entities; (2) targeting support from funding bodies with mandates specifically relevant to mountain areas; (3) developing proposals that engage with the needs and knowledge of Indigenous peoples in mountain areas; and (4) devising adaptation projects that address concurrent priorities related to sustainable development and disaster risk reduction. These opportunities were considered alongside several salient concerns about formal adaptation support mechanisms in an effort to provide a well-rounded assessment of the prospects for planned adaptations in high mountain communities.

We hope that this paper has helped to reveal the considerable opportunities for increasing the quantity and quality of adaptation support organized through the UNFCCC to high mountain communities. At the same time, there is a need for prudence. International adaptation support mechanisms and local communities are often worlds apart, literally and figuratively. Building bridges between these worlds may be appropriate in many instances, but our assessment also suggests potential perils that should be considered in efforts to address local adaptation needs through planned adaptation initiatives. Taking account of such complexities will require additional research examining the political economy of delivering adaptation 
support from global mechanisms through the state to local communities, the politics of securing state endorsement for the accreditation of organizations working in mountain areas, and the conditions under which autonomous adaptations might be superior to externally resourced interventions.

Acknowledgements We are extremely grateful for the effort of our local research partners Dhawa Gyanjen Lama and Tsering Dekyi Lama as well as community members in the upper Manaslu region, whose willingness to share information about their lives was very generous. We would like to thank 2 anonymous reviewers for constructive feedback, which improved the manuscript.

Availability of data and material Literature evaluated is available publicly or through academic databases.

Code availability N/A

Authors' contributions Dr. Graham McDowell—developed project idea and research methods and led data analysis and writing.

Dr. Leila Harris - contributed to project design and manuscript preparation.

Dr. Michele Koppes - contributed to project design and manuscript preparation.

Dr. Martin F. Price - contributed to project design and manuscript preparation.

Dr. Kai M.A. Chan - contributed to project design and manuscript preparation.

Mr. Dhawa Gyanjen Lama-local research partner, led data collection in Nepal.

Funding Open access funding provided by University of Zurich. The study was supported by funding from the Social Sciences and Humanities Research Council of Canada (SSHRC Vanier Canada Graduate Scholarship), the Canadian International Development Research Centre (IDRC Doctoral Research Award), and initiatives at the University of British Columbia: The Liu Institute for Global Issues, The Institute for Asian Research, and The Public Scholars Initiative.

\section{Compliance with ethical standards}

Conflict of interest The authors declare that they have no conflicts of interest.

Open Access This article is licensed under a Creative Commons Attribution 4.0 International License, which permits use, sharing, adaptation, distribution and reproduction in any medium or format, as long as you give appropriate credit to the original author(s) and the source, provide a link to the Creative Commons licence, and indicate if changes were made. The images or other third party material in this article are included in the article's Creative Commons licence, unless indicated otherwise in a credit line to the material. If material is not included in the article's Creative Commons licence and your intended use is not permitted by statutory regulation or exceeds the permitted use, you will need to obtain permission directly from the copyright holder. To view a copy of this licence, visit http://creativecommons.org/licenses/by/4.0/.

\section{References}

Adger WN (2006) Vulnerability. Glob Environ Chang 16:268-281

Adler C, Huggel C, Orlove B, Nolin A (2019) Climate change in the mountain cryosphere: impacts and responses. Reg Environ Chang 19:1225-1228

Ayers J, Forsyth T (2009) Community-based adaptation to climate change. Environ Sci Policy Sustain Dev 51: $22-31$

Bassett TJ, Fogelman C (2013) Déjà vu or something new? The adaptation concept in the climate change literature. Geoforum 48:42-53 
Belfer E, Ford JD, Maillet M, Araos M, Flynn M (2019) Pursuing an indigenous platform: exploring opportunities and constraints for indigenous participation in the UNFCCC. Glob Environ Politics 19:12-33

Bengtsson M (2016) How to plan and perform a qualitative study using content analysis. NursingPlus Open 2:814

Bennike RB (2017) Aftershock: reflections on the politics of reconstruction in northern Gorkha. HIMALAYA $37: 9$

Bennike RB (2018) Dangerous development. Republica 6

Bennike RB (2019) Himalayan futures: tourism and the anticipation of development. Can J Dev Stud/Rev Can Dév:1-17

Betsill M, Dubash NK, Paterson M, Asselt Hv, Vihma A, Winkler H (2015) Building productive links between the UNFCCC and the broader global climate governance landscape. Glob Environ Politics 15:1-10

Bolch T, Shea JM, Liu S, Azam FM, Gao Y, Gruber S, Immerzeel WW, Kulkarni A, Li H, Tahir AA (2019) Status and change of the cryosphere in the extended Hindu Kush Himalaya region, the Hindu Kush Himalaya assessment. Springer, pp 209-255

Carey M, Molden OC, Rasmussen MB, Jackson M, Nolin AW, Mark BG (2017) Impacts of glacier recession and declining meltwater on mountain societies. Ann Am Assoc Geogr 107:350-359

Chan KMA, Agard J, Liu J et al (2019) IPBES global assessment on biodiversity and ecosystem services chapter 5. Pathways towards a sustainable future. Intergovernmental Science-Policy Platform on Biodiversity and Ecosystem Services, Bonn, Germany, p 157

Childs G (2004) Tibetan diary: from birth to death and beyond in a Himalayan Valley of Nepal. University of California Press

Cohen-Shacham E, Walters G, Janzen C, Maginnis S (2016) Nature-based solutions to address global societal challenges. IUCN, Gland, Switzerland, p 97

Debarbieux B, Rudaz G (2015) The mountain: a political history from the enlightenment to the present. University of Chicago Press, Chicago

Díaz S, Settele J, Brondízio ES, Ngo HT, Agard J, Arneth A, Balvanera P, Brauman KA, Butchart SHM, Chan KMA, Garibaldi LA, Ichii K, Liu J, Subramanian SM, Midgley GF, Miloslavich P, Molnár Z, Obura D, Pfaff A, Polasky S, Purvis A, Razzaque J, Reyers B, Chowdhury RR, Shin Y-J, Visseren-Hamakers I, Willis KJ, Zayas CN (2019) Pervasive human-driven decline of life on earth points to the need for transformative change. Science 366:eaax3100

Dixit A, Subedi Y, Aryal N, Wenju R, Shrestha A (2016) Climate finance: fund flow from national to subnational level in Nepal. ISET-Nepal, Kathmandu

Donner SD, Kandlikar M, Webber S (2016) Measuring and tracking the flow of climate change adaptation aid to the developing world. Environ Res Lett 11:054006

Egan P, Price M (2017) Mountain ecosystem services and climate change: a global overview of potential threats and strategies for adaptation. UNESCO, Paris, p 33

Eisner E (1991) The enlightened eye: qualitative inquiry and the enhancement of educational practice. MacMillan, New York

Ensor JE, Wennström P, Bhatterai A, Nightingale AJ, Eriksen S, Sillmann J (2019) Asking the right questions in adaptation research and practice: seeing beyond climate impacts in rural Nepal. Environ Sci Pol 94:227-236

Eriksen SH, Nightingale AJ, Eakin H (2015) Reframing adaptation: the political nature of climate change adaptation. Glob Environ Chang 35:523-533

FAO (2015) In: Romeo R, Vita A, Testolin R, Hofer T (eds) Mapping the vulnerability of mountain peoples to food insecurity. FAO, Rome, p 68

Few R, Brown K, Tompkins EL (2007) Public participation and climate change adaptation: avoiding the illusion of inclusion. Clim Pol 7:46-59

Folke C, Carpenter SR, Walker B, Scheffer M, Chapin T, Rockstrom J (2010) Resilience thinking: integrating resilience, adaptability and transformability. Ecol Soc 15:20

Ford JD, Smit B (2004) A framework for assessing the vulnerability of communities in the Canadian arctic to risks associated with climate change. Arctic 57:389-400

Ford JD, Keskitalo E, Smith T, Pearce T, Berrang-Ford L, Duerden F, Smit B (2010) Case study and analogue methodologies in climate change vulnerability research. Wiley Interdiscip Rev Clim Chang 1:374-392

Ford JD, McDowell G, Jones J (2014) The state of climate change adaptation in the Arctic. Environ Res Lett 9: 104005

Ford J, Maillet M, Pouliot V, Meredith T, Cavanaugh A, Lwasa S, Llanos A, Berrang-Ford L, Carcamo C, Namanya DB, Harper S, Team IR (2016) Adaptation and indigenous peoples in the United Nations framework convention on climate change. Clim Chang 139:429-443

Ford JD, King N, Galappaththi EK, Pearce T, McDowell G, Harper SL (2020) The resilience of indigenous peoples to environmental change. One Earth 2:532-543 
Füssel H-M (2007) Adaptation planning for climate change: concepts, assessment approaches, and key lessons. Sustain Sci 2:265-275

Gagné K, Rasmussen MB, Orlove B (2014) Glaciers and society: attributions, perceptions, and valuations. Wiley Interdiscip Rev Clim Chang 5:793-808

Gardner J, Rhoades R, Stadel C (2013) People in mountains. In: Price MF, Byers AC, Friend DA, Kohler T, Price LW (eds) Mountain geography: physical and human dimensions. University of California Press, Berkeley, pp 267-300

GEF (2019a) Ecosystem-based adaptation for climate-resilient development in the Kathmandu Valley, Nepal

GEF (2019b) Projects. Global Environment Facility

Gentle P, Maraseni TN (2012) Climate change, poverty and livelihoods: adaptation practices by rural mountain communities in Nepal. Environ Sci Pol 21:24-34

Gioli G, Thapa G, Khan F, Dasgupta P, Nathan D, Chhetri N, Adhikari L, Mohanty SK, Aurino E, Scott LM (2019) Understanding and tackling poverty and vulnerability in mountain livelihoods in the Hindu Kush Himalaya, the Hindu Kush Himalaya assessment. Springer, pp 421-455

GoN (2011a) Climate change policy, 2011. Unofficial translation. Government of Nepal, Kathmandu

GoN (2011b) National framework on local adaptation plans for action. Ministry of Environment, Singhdurbar, p 56

Hewitt K, Mehta M (2012) Rethinking risk and disasters in mountain areas. J Alpine Res Rev Géogr Alpine

Hock R, Rasul G, Adler C, Cáceres B, Gruber S, Hirabayashi Y, Jackson M, Kääb A, Kang S, Kutuzov S, Milner A, Molau U, Morin S, Orlove B, Steltzer H, Contributing Authors (2019) High mountain areas chapter IPCC Special Report on the Oceans and Cryosphere in a Changing Climate (SROCC). Intergovernmental Panel on Climate Change (IPCC)

Huss M, Bookhagen B, Huggel C, Jacobsen D, Bradley R, Clague J, Vuille M, Buytaert W, Cayan D, Greenwood G (2017) Toward mountains without permanent snow and ice. Earth's Future 5:418-435

Jones HP, Hole DG, Zavaleta ES (2012) Harnessing nature to help people adapt to climate change. Nat Clim Chang 2:504-509

Jurt C, Burga MD, Vicuña L, Huggel C, Orlove B (2015) Local perceptions in climate change debates: insights from case studies in the Alps and the Andes. Clim Chang 133:511-523

Kates RW, Travis WR, Wilbanks TJ (2012) Transformational adaptation when incremental adaptations to climate change are insufficient. Proc Natl Acad Sci 109:7156-7161

Kaul V (2019) Holistically understanding and enhancing the adaptation of remote high-mountain communities to hydrometeorological extremes and associated geohazards in a changing climate. Department of Geography. University of Sheffield, p 265

Khan MR, Roberts JT (2013) Adaptation and international climate policy. Wiley Interdiscip Rev Clim Chang 4: 171-189

Lemos MC, Boyd E, Tompkins EL, Osbahr H, Liverman D (2007) Developing adaptation and adapting development. Ecol Soc 12:26

Lesnikowski A, Ford J, Biesbroek R, Berrang-Ford L, Maillet M, Araos M, Austin SE (2017) What does the Paris Agreement mean for adaptation? Clim Pol 17:825-831

Magnan AK, Ribera T (2016) Global adaptation after Paris. Science 352:1280-1282

Maharjan SK (2019) Local adaptation plan of action framework and process in the agriculture sector in Nepal. Int J Conserv Sci 10

Mahat TJ, Bláha L, Uprety B, Bittner M (2019) Climate finance and green growth: reconsidering climate-related institutions, investments, and priorities in Nepal. Environ Sci Eur 31:46

Matthews T, Lo AY, Byrne JA (2015) Reconceptualizing green infrastructure for climate change adaptation: barriers to adoption and drivers for uptake by spatial planners. Landsc Urban Plan 138:155-163

McDowell G, Koppes M (2017) Robust adaptation research in high mountains: integrating the scientific, social, and ecological dimensions of glacio-hydrological change. Water 9:739

McDowell G, Ford JD, Lehner B, Berrang-Ford L, Sherpa A (2013) Climate-related hydrological change and human vulnerability in remote mountain regions: a case study from Khumbu, Nepal. Reg Environ Chang 13: 299-310

McDowell G, Stephenson E, Ford J (2014) Adaptation to climate change in glaciated mountain regions. Clim Chang 126:77-91

McDowell G, Huggel C, Frey H, Wang FM, Cramer K, Ricciardi V (2019) Adaptation action and research in glaciated mountain systems: are they enough to meet the challenge of climate change? Glob Environ Chang 54:19-30

McDowell G, Koppes M, Harris L, Chan K, Price M, Lama D, Jiménez G (in review) Lived experiences of 'peak water' in the high mountains of Nepal and Peru 
Mills-Novoa M, Borgias SL, Crootof A, Thapa B, de Grenade R, Scott CA (2017) Bringing the hydrosocial cycle into climate change adaptation planning: lessons from two Andean mountain water towers. Ann Am Assoc Geogr 107:393-402

Mishra A, Appadurai AN, Choudhury D, Regmi BR, Kelkar U, Alam M, Chaudhary P, Mu SS, Ahmed AU, Lotia H (2019) Adaptation to climate change in the Hindu Kush Himalaya: stronger action urgently needed, the Hindu Kush Himalaya assessment. Springer, pp 457-490

MoE (2010a) Climate change vulnerability mapping for Nepal. Government of Nepal, Ministry of Environment (MoE), Kathmandu, p 96

MoE (2010b) National Adaptation Programme of Action (NAPA) to climate change. Government of Nepal, Ministry of Environment (MoE), Kathmandu, p 96

MoFE (2018) Nepal's National Adaptation Plan (NAP) process: reflecting on lessons learned and the way forward. Government of Nepal, Ministry of Forests and Environment (MoFE), NAP Global Network, Action on Climate Today (ACT) and Practical Action Nepal, Kathmandu, p 54

$\mathrm{MoH}$ (2015) Climate Change Health Adaptation Strategies and Action Plans of Nepal (2016 2020). Government of Nepal, Ministry of Health $(\mathrm{MoH})$, Kathmandu, p 38

Moser SC, Ekstrom JA (2010) A framework to diagnose barriers to climate change adaptation. Proc Natl Acad Sci 107:22026-22031

MoSTE (2014) Economic impact assessment of climate change in key sectors in Nepal. Government of Nepal, Ministry of Science, Technology and Environment (MoSTE), Kathmandu, p 25

Muccione V, Salzmann N, Huggel C (2016) Scientific knowledge and knowledge needs in climate adaptation policy: a case study of diverse mountain regions. Mt Res Dev 36:364-375

Nagoda S (2015) New discourses but same old development approaches? Climate change adaptation policies, chronic food insecurity and development interventions in northwestern Nepal. Glob Environ Chang 35:570579

Nagoda S, Nightingale AJ (2017) Participation and power in climate change adaptation policies: vulnerability in food security programs in Nepal. World Dev 100:85-93

Nightingale AJ (2017) Power and politics in climate change adaptation efforts: struggles over authority and recognition in the context of political instability. Geoforum 84:11-20

NPC (2011) Climate-resilient planning: a tool for long-term climate adaptation. Government of Nepal, National Planning Commission, Kathmandu, p 50

NTNC (2019) National Trust for Nature Conservation - Manaslu Conservation Area Project (MCAP)

O'Brien K, Leichenko RM (2000) Double exposure: assessing the impacts of climate change within the context of economic globalization. Glob Environ Chang 10:221-232

Ojha HR, Ghimire S, Pain A, Nightingale A, Khatri DB, Dhungana H (2016) Policy without politics: technocratic control of climate change adaptation policy making in Nepal. Clim Pol 16:415-433

Orlove B, Milch K, Zaval L, Ungemach C, Brugger J, Dunbar K, Jurt C (2019) Framing climate change in frontline communities: anthropological insights on how mountain dwellers in the USA, Peru, and Italy adapt to glacier retreat. Reg Environ Chang 19:1295-1309

Palazzi E, Mortarini L, Terzago S, Von Hardenberg J (2019) Elevation-dependent warming in global climate model simulations at high spatial resolution. Clim Dyn 52:2685-2702

Palomo I (2017) Climate change impacts on ecosystem services in high mountain areas: a literature review. Mt Res Dev 37:179-187

Payne G, Payne J (2004) Content analysis. Key Concepts Soc Res:51-55

Pepin N, Bradley RS, Diaz HF, Baraer M, Caceres EB, Forsythe N, Fowler H, Greenwood G, Hashmi MZ, Liu XD, Miller JR, Ning L, Ohmura A, Palazzi E, Rangwala I, Schöner W, Severskiy I, Shahgedanova M, Wang MB, Williamson SN, Yang DQ (2015) Elevation-dependent warming in mountain regions of the world. Nat Clim Chang 5:424-430

Plachta N (2018) Himalayan borderland communities: identity, belonging, and place among the Tsumpas. Institute for the Science of Religion and Central Asian Studies. University of Bern, p 260

Price MF, Kohler T (2013) Sustainable Mountain development. In: Price MF, Byers AC, Friend DA, Kohler T, Price LW (eds) Mountain geography: physical and human dimensions. University of California Press, Berkeley, pp 333-365

Rasul G, Pasakhala B, Mishra A, Pant S (2019) Adaptation to mountain cryosphere change: issues and challenges. Clim Dev:1-13

Ribot J (2011) Vulnerability before adaptation: toward transformative climate action. Glob Environ Chang 21: $1160-1162$

Ribot J (2014) Cause and response: vulnerability and climate in the Anthropocene. J Peasant Stud 41:667-705

Robson BA, Nuth C, Nielsen PR, Girod L, Hendrickx M, Dahl SO (2018) Spatial variability in patterns of glacier change across the Manaslu Range, Central Himalaya. Front Earth Sci 6:12 
Sapkota P, Keenan RJ, Paschen J-A, Ojha HR (2016) Social production of vulnerability to climate change in the rural middle hills of Nepal. J Rural Stud 48:53-64

Scott CA, Zhang F, Mukherji A, Immerzeel W, Mustafa D, Bharati L (2019) Water in the Hindu Kush Himalaya, the Hindu Kush Himalaya assessment. Springer, pp 257-299

Shawoo Z, Thornton TF (2019) The UN local communities and indigenous peoples' platform: a traditional ecological knowledge-based evaluation. Wiley Interdiscip Rev Clim Chang 10:e575

Shukla R, Sachdeva K, Joshi P (2017) Demystifying vulnerability assessment of agriculture communities in the Himalayas: a systematic review. Nat Hazards:1-21

Silwal P, Roberts L, Rennie HG, Lexer MJ (2019) Adapting to climate change: an assessment of local adaptation planning processes in forest-based communities in Nepal. Clim Dev 11:886-898

Smit B, Wandel J (2006) Adaptation, adaptive capacity and vulnerability. Glob Environ Chang 16:282-292

Smit B, Burton I, Klein RJ, Wandel J (2000) An anatomy of adaptation to climate change and variability. Clim Chang 45:223-251

Sovacool BK (2011) Hard and soft paths for climate change adaptation. Clim Pol 11:1177-1183

Sud R, Mishra A, Varma N, Bhadwal S (2015) Adaptation policy and practice in densely populated glacier-fed river basins of South Asia: a systematic review. Reg Environ Chang 15:825-836

Sutton A, Clowes M, Preston L, Booth A (2019) Meeting the review family: exploring review types and associated information retrieval requirements. Health Inf Libr J 36:202-222

Thornton TF, Manasfi N (2010) Adaptation genuine and spurious: demystifying adaptation processes in relation to climate change. Environ Soc Adv Res 1:132-155

Turner WR, Bradley BA, Estes LD, Hole DG, Oppenheimer M, Wilcove DS (2010) Climate change: helping nature survive the human response. Conserv Lett 3:304-312

UN Climate Change Secretariat (2017) Opportunities and options for integrating climate change adaptation with the Sustainable Development Goals and the Sendai Framework for Disaster Risk Reduction 2015-2030. United Nations Climate Change Secretariat, Bonn

UNFCCC (1992) United Nations Framework Convention on Climate Change

UNFCCC (2011) Cancun Agreements. United Nations Framework Convention on Climate Change

UNFCCC (2015) Paris Agreement in: United Nations Framework Convention on Climate Change (Ed.), Paris, p. 16

United Nations (2015) Transforming our world: the 2030 agenda for sustainable development, General Assembley 70 session. United Nations, Geneva, p 41

Vij S, Biesbroek R, Groot A, Termeer K (2018) Changing climate policy paradigms in Bangladesh and Nepal. Environmental Science \& Policy 81:77-85.

Vij S, Biesbroek R, Groot A, Termeer K, Parajuli BP (2019) Power interplay between actors: using material and ideational resources to shape local adaptation plans of action (LAPAs) in Nepal. Clim Pol 19:571-584

Weikmans R, Roberts JT (2019) The international climate finance accounting muddle: is there hope on the horizon? Clim Dev 11:97-111

Wilbanks TJ, Kates RW (2010) Beyond adapting to climate change: embedding adaptation in responses to multiple threats and stresses. Ann Assoc Am Geogr 100:719-728

Wymann von Dach S, Bachmann F, Alcántara-Ayala I, Fuchs S, Keiler M, Mishra A, Sötz E (2017) Safer lives and livelihoods in mountains: making the Sendai Framework for Disaster Risk Reduction work for sustainable mountain development. Centre for Development and Environment (CDE), University of Bern, Bern Open

Wymann von Dach S, Bracher CP, Peralvo M, Perez K, Adler C (2018) Leaving no one in mountains behind: localizing the SDGs for resilience of mountain people and ecosystems

Publisher's note Springer Nature remains neutral with regard to jurisdictional claims in published maps and institutional affiliations.

\section{Affiliations}

\section{Graham McDowell $^{1} \cdot$ Leila Harris $^{1} \cdot$ Michele Koppes $^{1} \cdot$ Martin F. Price $^{2} \cdot$ Kai M.A. Chan $^{1}$. Dhawa G. Lama ${ }^{3}$}

1 Institute for Resources, Environment, and Sustainability (IRES), University of British Columbia, Vancouver, Canada

2 Centre for Mountain Studies, Perth College, University of Highlands and Islands, Perth, Scotland

3 Asia Khamsang Tours \& Trekking, Kathmandu, Nepal 